\title{
Ascending palatine branch from the lingual artery with multiple other variations of the external carotid artery
}

\author{
C. Escoffier ${ }^{1}$, D. Hage², T. Tanaka3 , R.S. Tubbs ${ }^{3-7,10, ~ J . ~ I w a n a g a 2, ~ 4, ~ 8, ~} 9$ \\ ${ }^{1}$ College of Dentistry, University of Florida, Gainesville, FL, United States \\ ${ }^{2}$ Department of Neurosurgery, Tulane Centre for Clinical Neurosciences, Tulane University School of Medicine, \\ New Orleans, LA, United States \\ ${ }^{3}$ Department of Periodontology, College of Dentistry, University of Florida, Gainesville, FL, United States \\ ${ }^{4}$ Department of Neurology, Tulane Centre for Clinical Neurosciences, Tulane University School of Medicine, \\ New Orleans, LA, United States \\ ${ }^{5}$ Department of Anatomical Sciences, St. George's University, St. George's, Grenada, West Indies \\ ${ }^{6}$ Department of Structural and Cellular Biology, Tulane University School of Medicine, New Orleans, LA, United States \\ 'Department of Neurosurgery and Ochsner Neuroscience Institute, Ochsner Health System, \\ New Orleans, LA, United States \\ ${ }^{8}$ Dental and Oral Medical Centre, Kurume University School of Medicine, Kurume, Fukuoka, Japan \\ ${ }^{9}$ Division of Gross and Clinical Anatomy, Department of Anatomy, Kurume University School of Medicine, \\ Kurume, Fukuoka, Japan \\ ${ }^{10}$ Department of Surgery, Tulane University School of Medicine, New Orleans, LA, United States
}

[Received: 25 August 2021; Accepted: 20 October 2021; Early publication date: 16 November 2021]

\begin{abstract}
The external carotid artery (ECA) is the major blood supply for structures in the head and neck. Typically, it has 8 separate branches; but there are many anatomical variations, making it difficult to predict surgical outcomes and complications without 3-dimensional imaging. This case study focuses on a cadaver with multiple anatomical variations in the ECA, i.e., lingual, facial, occipital, ascending pharyngeal, and posterior auricular arteries, found during routine dissection of the right cadaveric neck. We also discuss the incidences of several other anatomical variations of the ECA branches and their surgical implications and potential complications. (Folia Morphol 2023; 82, 1: 205-210)
\end{abstract}

Key words: lingofacial trunk, external carotid artery, anatomy, variation, cadaver

\section{INTRODUCTION}

The external carotid artery (ECA) forms at the bifurcation of the common carotid artery (CCA) at the level of the fourth cervical vertebra. It has eight major branches that supply areas around the head, neck, and face. It terminates as it bifurcates into the maxillary artery, which supplies the maxillary region and several adjacent regions such as the oral cavity, and the superficial temporal artery, which supplies the area of the scalp overlying the temporal region $[12,13]$.

The ascending palatine artery is a branch of the facial artery, diverging soon after the facial artery branches off the ECA. It runs along the superior pharyngeal constrictor muscle and travels between the styloglossus and stylopharyngeus muscles. As it arrives at the levator veli palatini muscle it divides into two branches $[12,13]$. One continues along the

Address for correspondence: J. Iwanaga, DDS, PhD, Department of Neurosurgery, Tulane Centre for Clinical Neurosciences, Tulane University School of Medicine, 131 S. Robertson St. Suite 1300, New Orleans, LA 70112, United States, tel: 5049885565, fax: 5049885793, e-mail: iwanagajoeca@gmail.com This article is available in open access under Creative Common Attribution-Non-Commercial-No Derivatives 4.0 International (CC BY-NC-ND 4.0) license, allowing to download articles and share them with others as long as they credit the authors and the publisher, but without permission to change them in any way or use them commercially. 


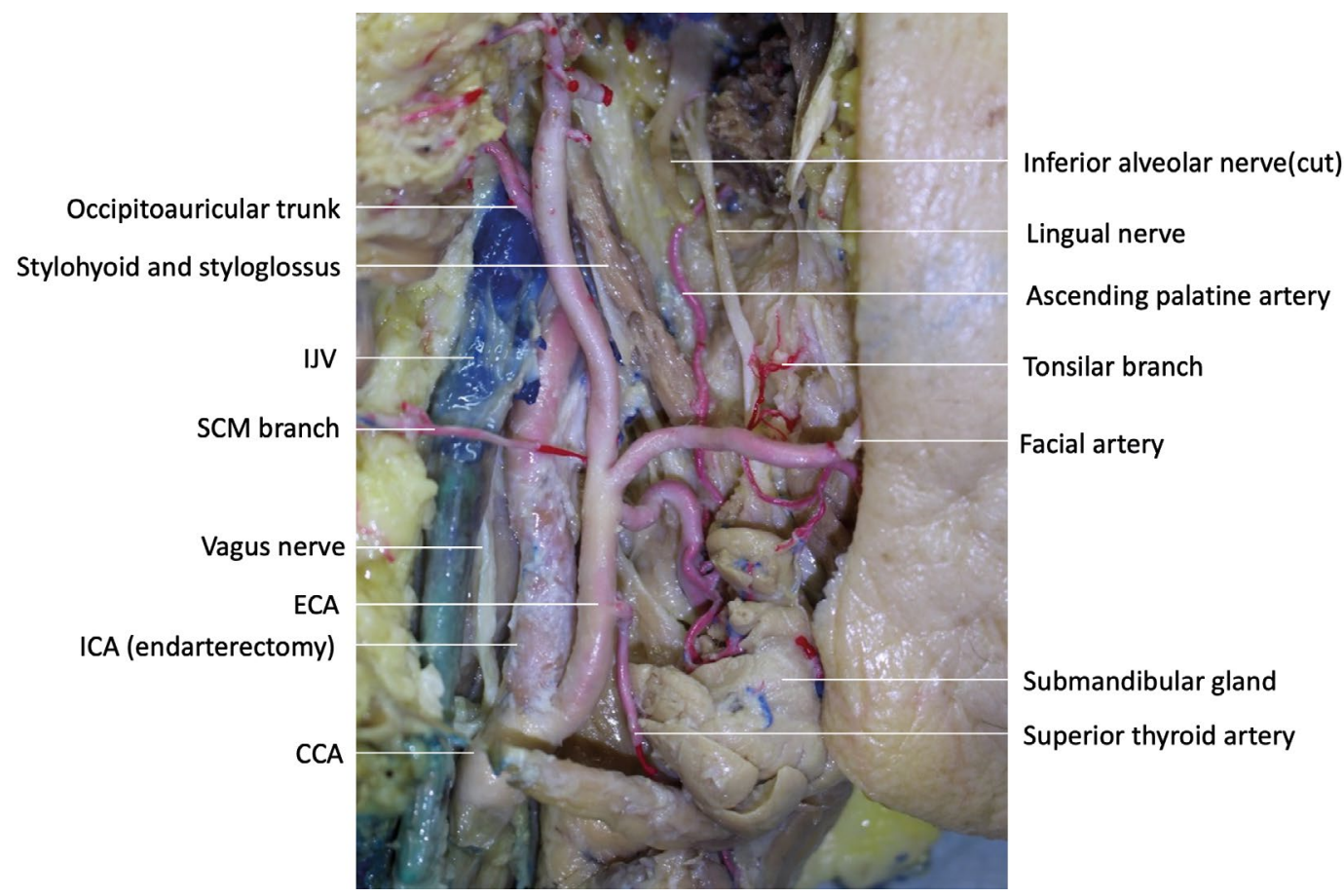

Figure 1. Right external carotid artery (ECA) with multiple variant branches; CCA — common carotid artery; ICA — internal carotid artery; IJV — internal jugular vein; SCM — sternocleidomastoid muscle.

pharynx to supply the palatine glands and the muscles of the soft palate, eventually anastomosing with the descending palatine branch of the maxillary artery. The other immediately pierces the pharynx to supply the palatine tonsil and auditory tube and later anastomoses with the tonsillar branch of the facial artery and the ascending pharyngeal artery [6].

The purpose of this case presentation is to discuss an anatomical variation found during a routine dissection that has important clinical implications for surgeries at the level of the angle of the mandible.

\section{CASE REPORT}

During routine dissection of the right cadaveric neck of a 72-year-old at death female, multiple anatomical variations of the ECA were noted (Figs. 1, 2). The cadaver had a history of endarterectomy of the right internal carotid. There was adhesion of the common facial vein and the hypoglossal nerve.

\section{Lingual and facial arteries}

A small branch arose from the lingual artery at the depth of the submandibular gland and bifurcated into the ascending palatine artery and $a$ branch to the submandibular gland (Fig. 3). The ascending palatine artery ran laterally to the stylohyoid and styloglossus muscles. This is an atypical presentation, as the as- cending palatine artery and the branch to the submandibular gland did not arise from the facial artery.

\section{Ascending pharyngeal artery}

The sternocleidomastoid branch arose from the ascending pharyngeal artery instead of the occipital artery (Fig. 4).

\section{Occipital and posterior auricular arteries}

The occipitoauricular trunk arose from the ECA at the level where the stylohyoid and styloglossus crossed it (Fig. 5).

\section{DISCUSSION}

\section{Embryology of the ECA}

The development of the ECA begins at weeks 3-5 in utero. The aortic sac gives rise to the aortic arches and the third aortic arch gives rise to the CCA, which later bifurcates into the internal and external carotid arteries. Most branches of the ECA originate from the third arch except for the maxillary artery, which arises from the first aortic arch [5].

\section{Other anatomical variations of the branches of the ECA}

There have been many studies aimed at identifying the incidences of different ECA variations. In an ana- 


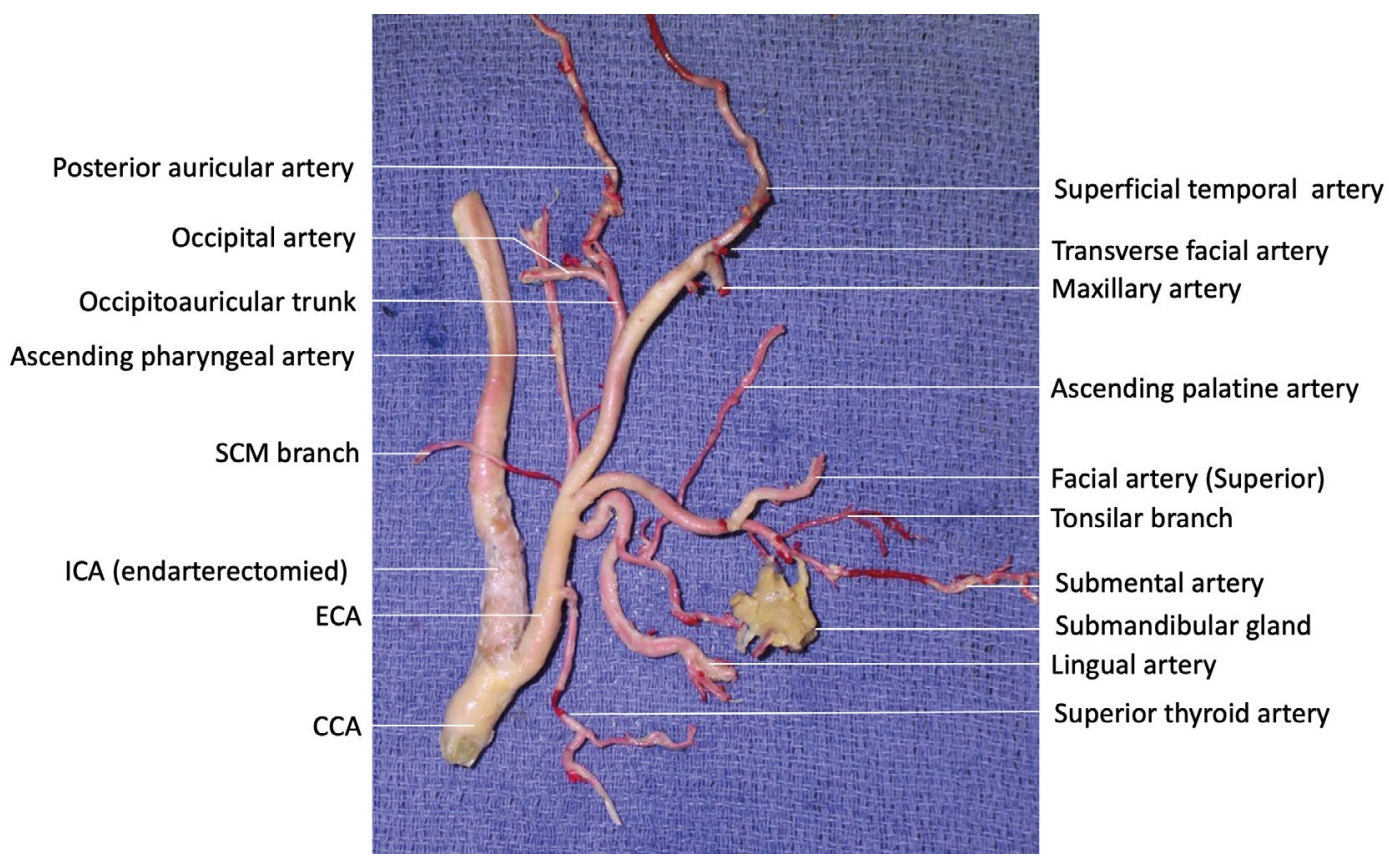

Figure 2. Right external carotid artery (ECA) with multiple variant branches after resection; CCA — common carotid artery; ICA — internal carotid artery; SCM — sternocleidomastoid muscle.

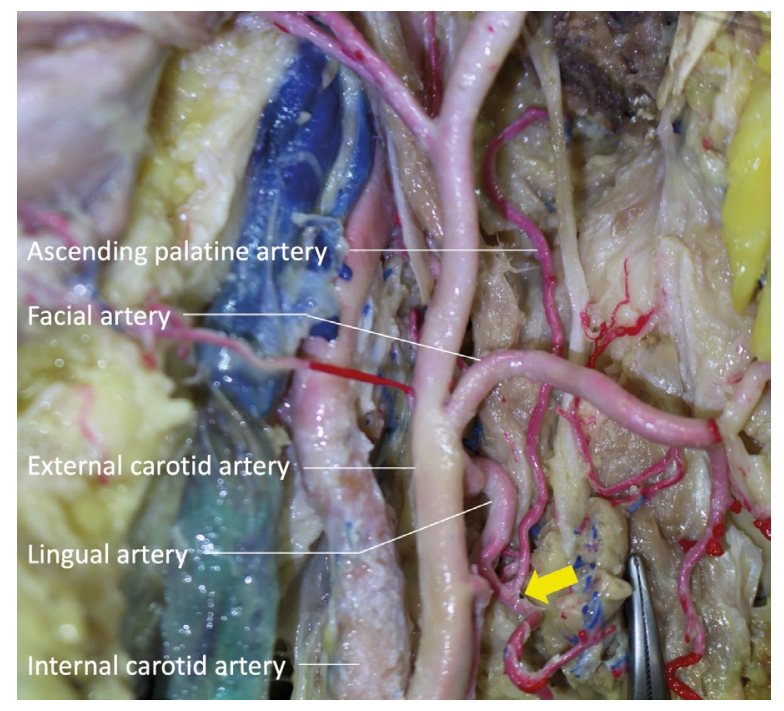

Figure 3. Ascending palatine artery arising from the lingual artery (arrow).

tomical study of 40 cadavers, Devadas et al. [4] identified and quantified various anatomical variations of ECA branching. They observed that only $75 \%$ of their specimens had an ECA origin at the level of the upper border of the thyroid cartilage, where it is expected. A higher-than-expected ECA origin was present in $25 \%$ cases; there were no cases with a lower-than-expected origin. It was noted that $78.75 \%$ of cases displayed separate origins for the anterior branches.
On the other hand, the linguofacial trunk was seen in $16 \%$ of the specimens, making it the most commonly observed variation, while a thyrolinguofaical trunk was seen in $1(1.25 \%)$ case; no thyrolingual trunks were present. Notably, a case with a thyrolinguofacial trunk was also reported by Baxla et al. [1]. The ascending pharyngeal artery was normal in $97.5 \%$ of their cases, but $1(1.25 \%)$ case had an unusually high origin above the carotid bifurcation, and another (1.25\%) displayed double pharyngeal arteries at the posteromedial aspect of the ECA. Other notable variations were a muscular branch to the masseter muscle from the ECA in the parotid region, a slender branch to the internal jugular veins from the ECA above the superior thyroid artery origin, and a superior laryngeal artery emerging directly from the ECA in $3.75 \%$ of cases [4].

Several anatomical variations of ECA branching patterns have also been described by Navakalyani et al. [10]. In their report, the facial and lingual arteries arose from a common linguofacial trunk in $8 \%$ of cases, and the superior thyroid and the lingual arteries arose from a common thyrolingual trunk in $1 \%$. They also observed the superior thyroid artery originating from the bifurcation of the CCA instead of the ECA in $8 \%$ of cases, and the ascending pharyngeal artery emerging from the occipital artery instead of the ECA in $1 \%$. In $5 \%$ of cases there was a variation in which the posterior auricular artery branched off the 


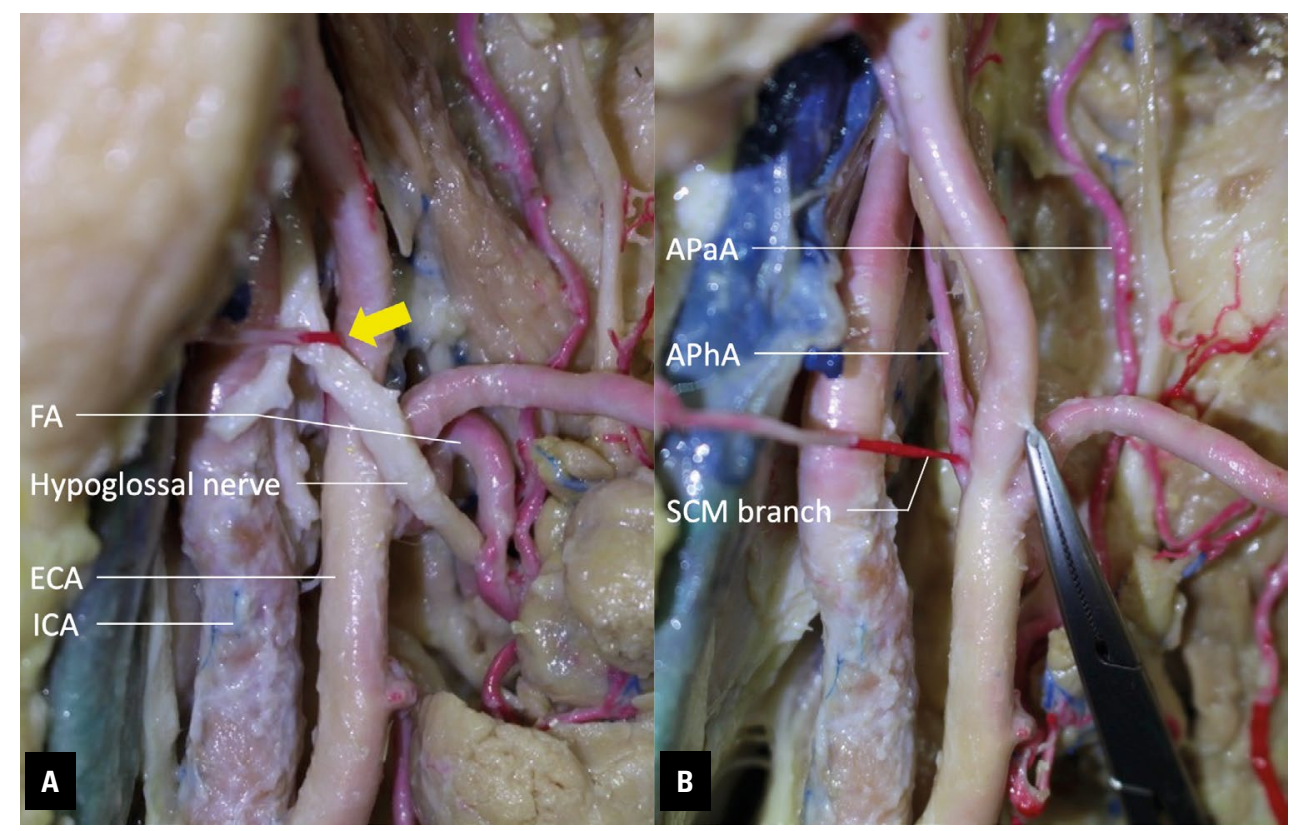

Figure 4. Sternocleidomastoid (SCM) branch arising from the ascending pharyngeal artery (APhA); $A$. SCM branch goes over the hypoglossal nerve (arrow); B. After resection of the hypoglossal nerve. The origin of the SCM is seen clearly; APaA — ascending palatine artery; ECA external carotid artery; FA — facial artery; ICA — internal carotid artery.

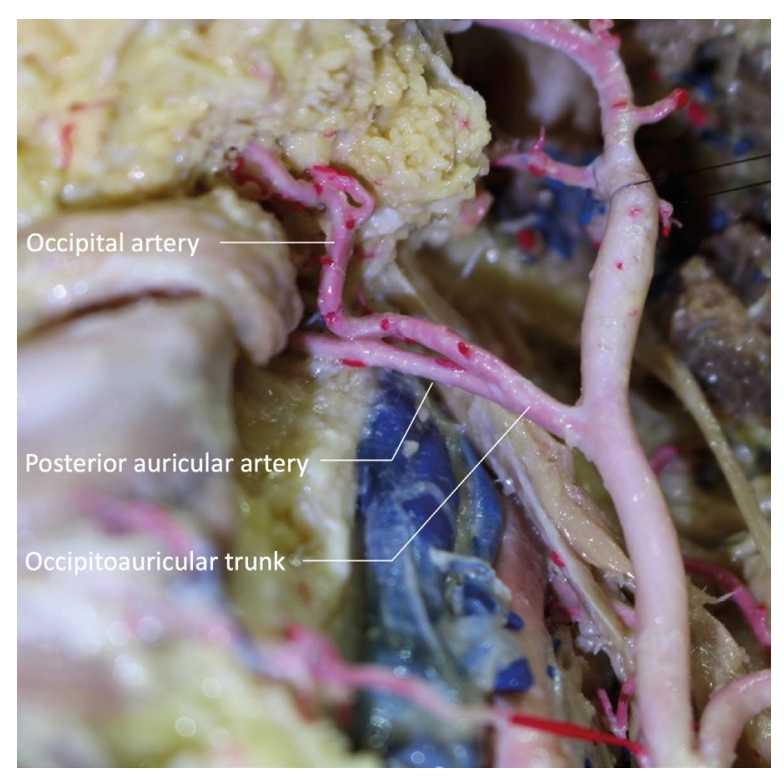

Figure 5. Occipitoauricular trunk.

occipital artery instead of branching separately off the ECA. They found no variations in the origin of the ECA, but like Devadas et al. [10] they noted the origin at a higher level than expected in $2 \%$ of cases.

In a study of 302 patients, Yamamoto et al. [14] determined the incidences of ECA branching patterns by analysing 532 ECAs using digital subtraction angiography. They classified these arteries into three categories $(A, B, C)$ based on the number of branches (two, three, four or more) emerging from the proximal ECA at a common point, the distal ECA counting as 1 branch [14]. Using this criterion, type $A$ (2 branches) is defined as all individual branches arising separately from the proximal ECA. They observed type A in 344 (64.6\%) ECAs in 237 (78.5\%) patients, type B in $134(25.2 \%)$ ECAs in $110(36.4 \%)$ patients, and type $C$ in $54(10.2 \%)$ ECAs in $49(16.2 \%)$ patients. Although type $C$ was the least prevalent, it had a shorter distance $(14.7 \pm 6.6 \mathrm{~mm})$ between the CCA and the bifurcation of the first branch of the ECA than type A $(21.8 \pm 15.6 \mathrm{~mm})$ or type B $(20.6 \pm 8.9 \mathrm{~mm})$. They also found that $96.3 \%$ of type C ECAs had a CCA bifurcation at the level of the junction of the third-fourth cervical vertebrae or higher, which was significantly higher than the bifurcation in type A or B. Because there are several anatomical variations, it is imperative that surgeons be aware of the type $C$ variation to avoid unexpected complications [14].

An anatomical variation of the ascending palatine artery, branching from the lingual artery instead of the facial artery, has been noted in previous literature. Unfortunately, we could find no more details of this variation [11].

Our present case contains several variations that have not yet been reported and are not the most commonly encountered. While variations such as the linguofacial, thyrolinguofacial, and thyrolingual 
trunks are gaining more exposure amongst surgeons, many others are possible. Each variant has important implications for surgeries of the head and neck such as thyroidectomies or reconstruction of a cervical aneurysm, so increasing our knowledge of these variations is imperative for reducing risks associated with head and neck surgery.

\section{Blood supply to the posterior palate}

The ascending palatine artery provides the main source of perfusion to the soft palate, specifically supplying the uvula, palatoglossus, palatopharyngeus, and the levator veli palatini muscle. This artery splits into two branches, the anterior and the posterior ascending palatine arteries. However, some studies have shown that the two branches do not always supply the soft palate simultaneously, which could be surgically significant [3]. The ascending pharyngeal artery also has another role; it has been found to supply the palatopharyngeus muscle [7]. Other arteries to note are the lesser palatine, the palatal branch of the ascending pharyngeal, and the tonsillar, which emerge beneath the mucosal layer and anastomose with the branches of the ascending palatine artery. This rich and interconnected blood supply reduces the risk of necrosis during palatoplasty surgeries [7].

\section{Clinical relevance}

The lingual and facial arteries are located in delicate regions of the head and neck, putting them at risk of causing life-threatening haemorrhages in the setting of trauma. Haemorrhages on the floor of the mouth can obstruct the airway and require emergency tracheostomy to maintain airway patency, so anatomical variations are important for physicians to consider when they plan for surgery or treat trauma cases [9]. Although the main complication of submandibulectomies is sialadenitis, it is imperative that surgeons be wary of vessels emerging from the lingual nerve at the level of the sublingual gland [6]. In our case study, the anatomical variation of the ascending palatine vessel emerging from the lingual artery at the submandibular gland would result in necrosis of the palate if it were severed during surgery.

\section{CONCLUSIONS}

Anatomical variations in the arteries supplying the palate can affect the outcome of surgeries such as palatoplasty in cleft palate patients and Le Fort I osteotomies. A study of the risk of palatal necrosis in Le Fort I osteotomies showed that $90 \%$ of patients had normal anatomy in which both the ascending palatine and ascending pharyngeal arteries supplied the area, while $10 \%$ were dependent on the ascending pharyngeal artery alone for a blood supply to the palate. This reduction in vascular supply can pose a huge risk if the ascending pharyngeal artery is ligated in a patient with the variation, whereas in patients with normal anatomy the ascending palatine artery simply provides a supplement [2].

\section{Acknowledgements}

The authors sincerely thank those who donated their bodies to science so that anatomical research could be performed. Results from such research can potentially increase mankind's overall knowledge that can then improve patient care. Therefore, these donors and their families deserve our highest gratitude [8].

\section{Conflict of interest: None declared}

\section{REFERENCES}

1. Baxla M, Kumari C, Kaler S. Bilateral thyrolinguofacial trunk: unusual and rare branching pattern of external carotid artery. Anat Cell Biol. 2018; 51(4): 302-304, doi: 10.5115/acb.2018.51.4.302, indexed in Pubmed: 30637166.

2. Bruneder S, Wallner J, Weiglein A, et al. Anatomy of the Le Fort I segment: Are arterial variations a potential risk factor for avascular bone necrosis in Le Fort I osteotomies? J Craniomaxillofac Surg. 2018; 46(8): 1285-1295, doi: 10.1016/j.jcms.2018.04.023, indexed in Pubmed: 29805066

3. Cho JH, Kim JW, Park HW, et al. Arterial supply of the human soft palate. Surg Radiol Anat. 2017; 39(7): 731-734, doi: 10.1007/s00276-016-1798-3, indexed in Pubmed: 28138793.

4. Devadas D, Pillay M, Sukumaran TT. A cadaveric study on variations in branching pattern of external carotid artery. Anat Cell Biol. 2018; 51(4): 225-231, doi: 10.5115/ acb.2018.51.4.225, indexed in Pubmed: 30637155.

5. Hanneman K, Newman B, Chan F. Congenital variants and anomalies of the aortic arch. Radiographics. 2017; 37(1): 32-51, doi: 10.1148/rg.2017160033, indexed in Pubmed: 27860551.

6. Hernando M, Echarri $R$, Taha $M$, et al. Surgical complications of submandibular gland excision. Acta Otorrinolaringologica. 2012; 63(1): 42-46, doi: 10.1016/j. otoeng.2012.01.009.

7. Huang $\mathbf{M H}$, Lee ST, Rajendran K. Clinical implications of the velopharyngeal blood supply: a fresh cadaveric study. Plast Reconstr Surg. 1998; 102(3): 655-667, doi: 10.1097/00006534-199809030-00007, indexed in Pubmed: 9727428. 
8. Iwanaga J, Singh V, Takeda $S$, et al. Acknowledging the use of human cadaveric tissues in research papers: Recommendations from anatomical journal editors. Clin Anat. 2021; 34(1): 2-4, doi: 10.1002/ca.23671, indexed in Pubmed: 32808702.

9. Mawaddah A, Goh BS, Kew TY, et al. Isolated blunt lingual artery injury secondary to a road traffic accident: diagnostic and therapeutic approach. Malays J Med Sci. 2012; 19(2): 77-81.

10. Navakalyani T, Janaki V, Sumalatha Dr. Variant branching patterns of external carotid artery - pharyngo-occipital trunk and occipito - auricular trunk. IOSR J Dental Med Sci. 2016; 15(08): 44-47, doi: 10.9790/0853-1508064447.
11. Tubbs RS, Shoja MM, Loukas M. ed. Bergman's Comprehensive Encyclopedia of Human Anatomic Variation. John Wiley Sons 2016.

12. Uflacker R. ed. Arteries of the head and neck. Atlas of Vascular Anatomy: An Angiographic Approach 2007.

13. von Arx T, Tamura K, Yukiya O, et al. The face - a vascular perspective. A literature review. Swiss Dent J. 2018; 128(5): 382-392.

14. Yamamoto $D$, Koizumi $H$, Ishima $D$, et al. Angiographic characterization of the external carotid artery: special attention to variations in branching patterns. Tohoku J Exp Med. 2019; 249(3): 185-192, doi: 10.1620/tjem.249.185, indexed in Pubmed: 31761818. 